\title{
EDITORIAL
}

\section{Policy Regarding Climate-Related Research}

Recently, there has been some confusion concerning AMS policy with respect to climaterelated manuscripts which have been submitted for publication in the Society's journals. Therefore, the editors of MWR, JCAM and JAS are simultaneously publishing the following statement in order to clarify this policy:

Manuscripts which are climate-related and emphasize interannual variability and shorter time scales should be submitted to MONTHLY WEATHER REVIEW. The only exception are those submissions which emphasize socio-economic aspects of climate which should be submitted to the JOURNAL OF CLIMATE AND APPLIED METEOROLOGY in all cases. Manuscripts which are climate-related and emphasize time scales longer than those associated with interannual variability should also be submitted to the JOURNAL OF CLIMATE AND APPLIED METEOROLOGY. Manuscripts which emphasize basic research related to the physics and dynamics of climate should continue to be submitted to the JOURNAL OF THE ATMOSPHERIC SCIENCES.

Roger A. Pielke Chief Editor MWR
Alan D. Hecht

Co-Chief Editor JCAM

Bernard A. Silverman

Co-Chief Editor JCAM
J. Michael Fritsch

Co-Chief Editor JAS

Peter J. Webster

Co-Chief Editor JAS 